\title{
HPLC Determination of Pitavastatin Calcium in Pharmaceutical Dosage Forms
}

\author{
Nanjappan Satheesh Kumar ${ }^{1,2 *}$, Narayanan Nisha ${ }^{3}$, Jayabalan Nirmal ${ }^{4}$, Narayanan Sonali ${ }^{5}$ and $\mathrm{J} \mathrm{Bagyalakshmi}^{2}$ \\ ${ }^{1}$ Department of Pharmaceutical Analysis, NIPER-Hyderabad \\ ${ }^{2}$ Department of Pharmaceutical Analysis, College of Pharmacy, SRIPMS, Coimbatore-641 044, Tamil Nadu, India \\ ${ }^{3}$ Department of Pharmaceutical Technology, Jadavpur university, Kolkata-700 032, India \\ ${ }^{4}$ Department of Ocular Pharmacology and Pharmacy, Dr. R. P. Centre, All India Institute of Medical Sciences, New Delhi-110029, India \\ ${ }^{5}$ Department of Neurobiochemistry, Neuroscience Centre, All India Institute of Medical Sciences, New Delhi-110029, India
}

\begin{abstract}
A simple, sensitive, reliable and rapid reversed-phase high-performance liquid chromatographic (RP-HPLC) method has been developed and validated for the determination of pitavastatin calcium using paracetamol as internal standard. The chromatographic system consisted of Shimadzu LC-10ATVP Pump, SPD-M10 AVP with PDA detector. Separation was achieved on the phenomenex $C_{18}(250 \times 4.60), 5 \mu$ particle size column in isocratic mode at room temperature. The sample was introduced through an injector valve with a $20 \mu \mathrm{l}$, sample loop. $0.5 \%$ Acetic acid: Acetonitrile 35:65 (\%, v/v), was used as mobile phase with flow rate of $1 \mathrm{ml} / \mathrm{min}$. UV detection was performed at $245 \mathrm{~nm}$. A calibration graph was plotted which showed a linearity range between 1-5 $\mu \mathrm{g} / \mathrm{ml}$ with the correlation coefficient of 0.9986 . The LOD was $5 \mathrm{ng} / \mathrm{ml}$, while the LOQ was $20 \mathrm{ng} / \mathrm{ml}$. Validation studies revealed the method is specific, rapid, reliable, and reproducible. To study the validity of the method, recovery studies and repeatability studies were carried out using the same optimum conditions. The system suitability studies were also calculated which includes column efficiency, resolution, capacity factor and peak asymmetrical factor. Therefore the proposed method is reliable, rapid, precise and selective so may be used for the quantitative analysis of pitavastatin calcium.
\end{abstract}

Keywords: HPLC; Pitavastatin calcium; Pharmaceutical dosage form; Method Validation

\section{Introduction}

Pitavastatin is a new synthetic 3-hydroxy-3-methyl glutaryl coenzyme A reductase inhibitor, it is chemically (3R, 5S)-7-(2cyclopropyl-4-(4-fluorophenyl) quinolin-3-yl) - 3,5-dihydroxy 6(E) -heptenoic acid calcium salt (Figure 1). Metabolism of pitavastatin by the cytochrome $\mathrm{P} 450$ (CYP) system is minimal, principally through CYP 2C9, with little involvement of the CYP 3A4 isoenzyme, potentially reducing the risk of drug-drug interactions between pitavastatin and other drugs known to inhibit CYP enzymes $[1,2]$. [3] investigated the effect of repeated intake of grapefruit juice (GFJ) on the pharmacokinetics of pitavastatin and atorvastatin in Japanese subjects. The Plasma concentrations of pitavastatin acid and lactone, atorvastatin acid and lactone, and 2-hydroxy atorvastatin acid were quantified by the liquid chromatography-mass spectrometry methods. The mobile phase consist of acetonitrile and either $0.1 \%$ ammonium hydroxide in water (for pitavastatin compounds) or $10 \mathrm{~mm}$ ammonium acetate with $0.4 \%$ ammonia hydroxide in water (for atorvastatin) were used [3]. LC-MS/MS method with electrospray ionization (ESI) were developed for the simultaneous determination of pitavastatin and its lactone in human plasma and urine. The calibration curves of pitavastatin and its lactone were obtained in the concentration range

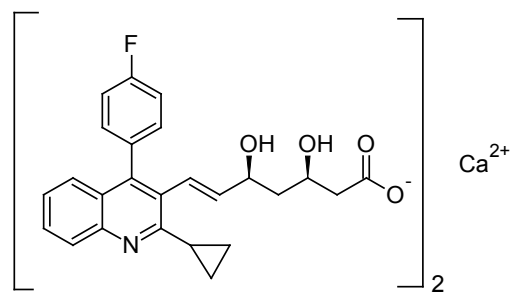

Figure 1: Chemical structure of pitavastatin calcium of 1-200 ng/ml, with a lower limit of quantitation of $1 \mathrm{ng} / \mathrm{ml}$ using methanol- $0.2 \%$ acetic acid in water (70: $30, \mathrm{v} / \mathrm{v})$ as the mobile phase [4]. [5] studied the pharmacokinetics of pitavastatin in patients with liver cirrhosis [5]. [6] studied the inhibitory effect of NK-104, a potent inhibitor of HMG-CoA reductase, on taxol metabolism were examined using radio-TLC. This method is described for in vitro measurement of taxol metabolites as an alternative to the commonly used HPLC assay [6]. A simple and sensitive column-switching HPLC method were developed for the simultaneous determination of NK-104 (HMGCoA reductase inhibitor) and its lactone in human and dog plasma. The calibration curves of NK-104 and NK-104 lactone were linear over the ranges 0.5 to $100 \mathrm{ng} / \mathrm{ml}$ for human plasma samples and 0.5 to $500 \mathrm{ng} / \mathrm{ml}$ for dog plasma, respectively [7]. [8] reported an analytical method for the determination of the drug from human plasma making use of the fluorescent property of the drug. Plasma is extracted from the drug using ethyl acetate and then analyzed by reversed-phase high performance liquid chromatography (HPLC) with fluorescence detection using $\mathrm{C}_{18}$ HPLC column with gradient flow of mobile phase (0.01 mol/L monobasic potassium phosphate $(\mathrm{pH} 3.20)$ acetonitrile, $63: 37, \mathrm{v} / \mathrm{v})[8]$. HPTLC determination of pitavastatin calcium in tablet dosage form were studied with the mobile phase of ethyl acetatemethanol-ammonia-1 drop formic acid (7:2:0.8) [9]. Another HPTLC method were developed by [10] in that method they used toluene-

${ }^{*}$ Corresponding author: Dr. N. Satheesh Kumar M. Pharm., Department of Pharmaceutical Analysis,National Institute of Pharmaceutical Education and Research, Balanagar,Hyderabad-500037,India, E-mail: satheshrx@gmail.com

Received December 28, 2010; Accepted April 05, 2011; Published April 08, 2011

Citation: Kumar NS, Nisha N, Nirmal J, Sonali N, Bagyalakshmi J (2011) HPLC Determination of Pitavastatin Calcium in Pharmaceutical Dosage Forms. Pharm Anal Acta 2:119. doi:10.4172/2153-2435.1000119

Copyright: (c) 2011 Kumar NS, et al. This is an open-access article distributed under the terms of the Creative Commons Attribution License, which permits unrestricted use, distribution, and reproduction in any medium, provided the original author and source are credited. 
methanol-glacial acetic acid 7.6:2.36:0.04 (v/v) as mobile phase and quantified at $238 \mathrm{~nm}$ [10]. HPLC and UV Spectroscopy method has been reported for Pitavastatin calcium in tablet formulation by [11]. In that study [11] developed a method with different mobile phase containing acetonitrile-water-triethylamine $(80+19.8+0.2, \mathrm{v} / \mathrm{v} / \mathrm{v})$, adjusted to $\mathrm{pH} 3.5+/-0.05$ with orthophosphoric acid at a flow rate of $1.5 \mathrm{ml} / \mathrm{min}$ were used for the separation of Pitavastatin calcium. The disadvantage of the method is that its run time is about $5.70 \mathrm{~min}$. Our study is to report an isocratic RP-LC method for the estimation of Pitavastatin Calcium using paracetamol as internal standard and the mobile phase consist of $0.5 \%$ Acetic acid: Acetonitrile 35:65 (\%, v/v), with the flow rate of $1 \mathrm{ml} / \mathrm{min}$. The retention time of Paracetamol and Pitavastatin Calcium were 2.5 and 4.2 min respectively. And it shows good peak purity and correlation. The developed method is simple, rapid, accurate and sensitive for estimating Pitavastatin calcium in tablet formulations than the previously reported method.

\section{Experimental}

\section{Chemicals and reagents}

Pitavastatin calcium was from Micro Laboratories. HPLC-grade Acetonitrile and methanol was purchased from Merck, India. Highpurity water was prepared using Millipore purification system. Other chemicals and reagents were of AR grade Pitava 1 and Flovas $1 \mathrm{mg}$ were obtained commercially.

\section{Instrumentation and chromatographic conditions}

HPLC analysis was performed on a Shimadzu LC-10ATVP pump, SPD-M10 AVP with PDA detector. Separation was achieved on the phenomenex $\mathrm{C}_{18}(250 \times 4.60) ; 5 \mu$ particle size column at room temperature with the mobile phase constituted by $0.5 \%$ acetic acid: acetonitrile (35:65) at the flow rate of $1 \mathrm{ml} / \mathrm{min}$. The mobile phase was filtered through $0.45 \mu \mathrm{m}$ nylon filter (Millipore, USA) and degassed by sonication prior to use. The detection was performed at $245 \mathrm{~nm}$. The Standard and sample was introduced through an injector valve with a $20 \mu$ l, sample loop. Data acquisition was performed using CLASS-VP software by the measurement of peak areas.

\section{Preparation of standard solution}

Standard stock solution of pitavastatin calcium and paracetamol $(1000 \mu \mathrm{g} / \mathrm{ml})$ was prepared in mobile phase containing $0.5 \%$ Acetic acid: Acetonitrile 35:65 (\%,v/v). Working standard solutions for the calibration curve were prepared by dilution of the above stock solution in a range of $1-5 \mu \mathrm{g} / \mathrm{ml}$ with mobile phase. To each dilution a fixed concentration of $1 \mu \mathrm{g} / \mathrm{ml}$ of internal standard paracetamol was added.

\section{Preparation of sample solution}

Twenty tablets of Pitava and Flovas containing $1 \mathrm{mg}$ of Pitavastatin calcium were weighed to get the average weight and then powdered. An amount of powder equivalent to $1 \mathrm{mg}$ of Pitavastatin calcium was transferred to a $100 \mathrm{ml}$ volumetric flask with $50 \mathrm{ml}$ mobile phase and shaken for $10 \mathrm{~min}$, followed by making up to volume with mobile phase. This solution was filtered using $0.2 \mu$ membrane filter. From this $1 \mathrm{ml}$ were pipetted out and transferred to $10 \mathrm{ml}$ volumetric flask, $1 \mathrm{ml}$ of internal standard solution $(\mu \mathrm{g} / \mathrm{ml})$ was added to each and made up to the volume to get the concentration of $1 \mu \mathrm{g} / \mathrm{ml}$ of Pitavastatin calcium.

\section{Method development and choice of internal standard}

A variety of mobile phases and internal standards were investigated in the development of an HPLC method suitable for analysis of
Pitavastatin Calcium in the tablet formulations. Finally, the condition adopted was $0.5 \%$ acetic acid: acetonitrile $35: 65(\%, \mathrm{v} / \mathrm{v})$, at the flow rate of $1 \mathrm{ml} / \mathrm{min}$. Paracetamol was selected as the suitable internal standard for this method.

\section{Method validation}

The method was validated for the parameters like specificity, range and linearity, limit of detection (LOD), limit of quantitation (LOQ), accuracy, and precision based on ICH/CPMP guidelines [12-15].

\section{Results and Discussion}

For RP-HPLC of Pitavastatin Calcium, various mobile phases were tried like methanol-water, 75:25 (\% v/v), acetonitrile - water, 75:25, methanol - water, 50:50, methanol - water, 95:5, methanol - phosphate buffer ( $\mathrm{pH} 3.5-6.5), 80: 20$, and acetonitrile - phosphate buffer ( $\mathrm{pH}$ 3.5-6.5), 80:20. The suitability of the mobile phase was decided on the basis of the sensitivity of the assay, suitability for stability studies, time required for the analysis, ease of preparation, and use of readily available cost-effective solvents. The same solvent mixture was used for extraction of the drug from the formulation containing excipients. Among the various mobile phases used, the mobile phase containing 0.5 $\%$ acetic acid and acetonitrile in the ratio of 35:65 (v/v) was found to be best for analysis, at the flow rate of $1 \mathrm{ml} / \mathrm{min}$. An injection volume of 20 $\mu \mathrm{l}$ and UV detection at $245 \mathrm{~nm}$ was used. For choosing an appropriate internal standard for the analysis of Pitavastatin Calcium, four drugs like Aspirin, Diclofenac Sodium, Paracetamol and Nimuslide were used. Among these, Paracetamol was chosen because it met all the typical requirements of an internal standard. It was stable during the analysis, readily available, was well resolved, its peak shape was good (tailing factor 1.24), and its elution time was short. The developed method was also found to be specific, accurate, precise and robust with acceptable values of LOD and LOQ.

\section{Linearity}

Linearity of the proposed method was verified by analyzing five solutions in the range of $1-5 \mu \mathrm{g} / \mathrm{ml}$ for pitavastatin calcium $(1,2$, 3, 4 and $5 \mu \mathrm{g} / \mathrm{ml}$ ). Each concentration was made in triplicate. Peak area ratios of standards compounds were plotted against theoretical concentration of standards. The linearity was expressed as a correlation coefficient by linear regression analysis. A calibration graph was plotted which showed a linearity range between $1-5 \mu \mathrm{g} / \mathrm{ml}$ with the correlation coefficient of $r^{2}=0.9986$.

\begin{tabular}{|l|l|l|}
\hline $\begin{array}{l}\text { Concentration }[\boldsymbol{\mu g} / \\
\mathbf{m L}]\end{array}$ & $\begin{array}{l}\text { Intraday precision } \\
(\mathrm{RSD}[\%] \mathbf{n = 3})\end{array}$ & $\begin{array}{l}\text { Interday precision (RSD [\%] } \\
\mathbf{n = 3})\end{array}$ \\
\hline 1 & 0.93 & 1.32 \\
\hline 2 & 0.72 & 1.28 \\
\hline 3 & 0.81 & 1.16 \\
\hline
\end{tabular}

Table1: Result from determination of precision of analysis of pitavastatin calcium.

\begin{tabular}{|l|l|l|l|l|l|}
\hline Sample & $\begin{array}{l}\text { Label claim [mg } \\
\text { per tablet] }\end{array}$ & $\begin{array}{l}\text { Initial amount } \\
{[\mu \mathbf{g} / \mathbf{m l}]}\end{array}$ & $\begin{array}{l}\text { Amount } \\
\text { added [\%] }\end{array}$ & $\begin{array}{l}\text { Recovery } \\
{[\%]}\end{array}$ & $\begin{array}{l}\text { RSD } \\
{[\%]}\end{array}$ \\
\hline & & 2 & 0 & 99.27 & 0.14 \\
Brand I & & 2 & 80 & 99.86 & 0.23 \\
[PITAVA] & 1 & 2 & 100 & 99.91 & 0.08 \\
& & 2 & 120 & 99.79 & 0.05 \\
& & 2 & 0 & 99.48 & 0.17 \\
Brand II & 1 & 2 & 80 & 99.70 & 0.21 \\
[FLOVAS] & & 2 & 100 & 99.87 & 0.27 \\
& & 2 & 120 & 99.43 & 0.12 \\
\hline
\end{tabular}

Table 2: Result from recovery studies. 


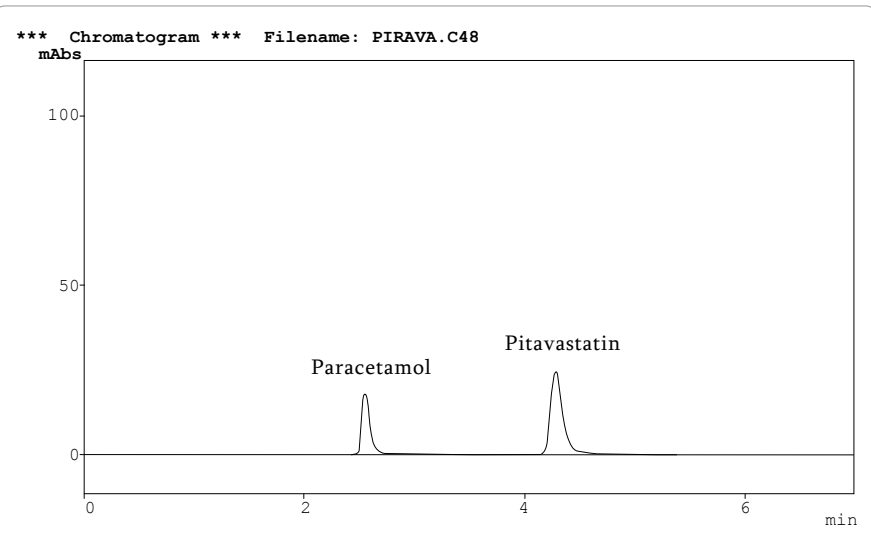

Figure 2: Typical chromatogram obtained from a standard solution of pitavastatin calcium ( $2 \mu \mathrm{g} / \mathrm{ml}$ ).

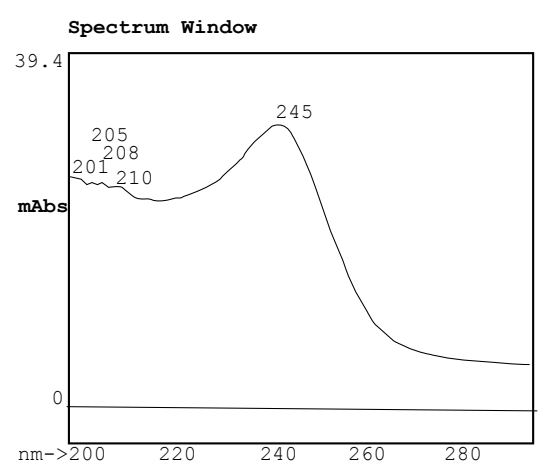

Figure 3: Typical absorption spectrum obtained from standard pitavastatin calcium solution.

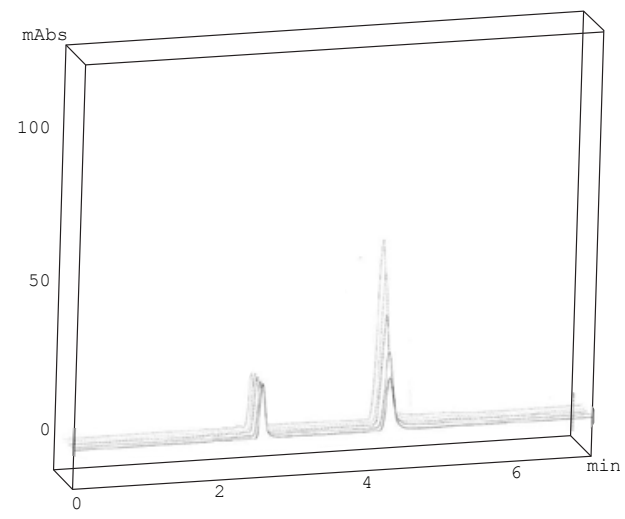

Figure 4: Overlay chromatogram of paracetamol and pitavastatin calcium.

\section{Limit of detection and limit of quantification}

The sensitivity of measurement of pitavastatin calcium by use of proposed method was estimated in terms of the limit of quantification (LOQ) and the lowest concentration detected under the chromatographic condition as the limit of detection (LOD). The LOQ and LOD were calculated by the use of equations $\mathrm{LOD}=3 \times \mathrm{N} / \mathrm{B}$ and LOQ $=10 \times \mathrm{N} / \mathrm{B}$ where $\mathrm{N}$ is the standard deviation of the peak area of the drug $(n=3)$, taken as a measure of noise and $B$ is the slope of the corresponding calibration plot. Solutions of Pitavastatin Calcium were prepared in the range of 2 to $500 \mathrm{ng} / \mathrm{ml}$ and injected in triplicate.
Average peak area of three analyses was plotted against concentration. The limit of quantification (LOQ) was $20 \mathrm{ng}$ and limit of detection (LOD) was $5 \mathrm{ng}$.

\section{Precision}

Precision was measured by analysis of sample solution containing Pitavastatin Calcium at concentrations covering the entire calibration range. The precision of the method in terms of intra day variation (\% CV) was determined by analysis of pitavastatin calcium standard solution $1-5 \mu \mathrm{g} / \mathrm{ml}(\mathrm{n}=6)$. Inter-day precision (\% CV) was assessed by analysis of the same solution on three different days. The results of precision studies are expressed in Table 1. The results showed that the proposed method is highly reproducible. Intra-day and Inter-day precision ranged from 0.72 to $0.93 \%$ and 1.16 to $1.32 \%$ respectively. Intra-day and inter-day precision was also within acceptability criteria of $\% \mathrm{RSD} \leq 2.0$ and $\leq 3.0$, respectively, indicating method precision was good [16].

\section{Accuracy}

The accuracy of the method was determined by analysis of standard at three different levels, ie. Multiple level recovery studies. A stock solution of a tablet formulation was prepared containing $2 \mu \mathrm{g} / \mathrm{ml}$ Pitavastatin Calcium. Amount of standard drug solution equivalent to $80 \%, 100 \%$ and $120 \%$ of the concentration in the table solution were added and recovery [\%] was determined. Values were found to be within the limit given in (Table 2). Intra-day and inter-day accuracy were within acceptability criteria for bias, $\pm 5 \%$ [16].

\section{Specificity}

The mobile phase designed for the method resolved the drug very efficiently, as is shown in (Figure 2). The retention time of Paracetamol and Pitavastatin Calcium were 2.5 and 4.2 min respectively and typical absorption spectrum and overlay chromatogram of pitavastatin calcium is shown in (Figure 3 and 4). The wavelength $245 \mathrm{~nm}$ was selected for the detection because it resulted in better detection sensitivity for the drug.

\section{Repeatability}

The repeatability of sample application was assessed by injecting $2 \mu \mathrm{g} / \mathrm{ml}$ of Pitavastatin Calcium six times. The RSD [\%] for peak-area value of pitavastatin calcium were found to be 0.93 and 0.96 respectively.

\section{Conclusion}

The developed HPLC methods for Pitavastatin Calcium in tablet formulation using mobile phase $0.5 \%$ acetic acid: acetonitrile 35:65 $(\%, v / v)$, at the flow rate of $1 \mathrm{ml} / \mathrm{min}$. A calibration graph was plotted which showed a linearity range between $1-5 \mu \mathrm{g} / \mathrm{ml}$ with the correlation coefficient of 0.9986 . The proposed method is simple, sensitive and accurate with good precision and is suitable for routine analysis of Pitavastatin Calcium in formulations.

\section{Acknowledgments}

I would like to thank all the authors for their support and providing the necessary information to perform this study.

\section{References}

1. Schachter M (2005) Chemical, pharmacokinetic and pharmacodynamic properties of statins: an update. Fundam Clin Pharmacol 19: 117-125.

2. Mukhtar RY, Reid J, Reckless JP (2005) Pitavastatin. Int J Clin Pract 59 239-252. 
Citation: Kumar NS, Nisha N, Nirmal J, Sonali N, Bagyalakshmi J (2011) HPLC Determination of Pitavastatin Calcium in Pharmaceutical Dosage Forms. Pharm Anal Acta 2:119. doi:10.4172/2153-2435.1000119

3. Ando H, Tsuruoka S, Yanagihara H, Sugimoto K, Miyata M, et al. (2005) Effects of grapefruit juice on the pharmacokinetics of pitavastin and atorvastatin. $\mathrm{Br} \mathrm{J}$ Clin Pharmacol 60: 494-497.

4. Tian L, Huang Y, Jia Y, Hua L, Li Y (2008). Development and validation of a liquid chromatography-tandem mass spectrometric assay for pitavastatin and its lactone in human plasma and urine. J Chromatogr B Analyt Technol Biomed Life Sci 865: 127-132.

5. Hui CK, Cheung BM, Lau GK (2005) Pharmacokinetics of pitavastatin in subjects with Child-Pugh A and B cirrhosis. Br J Clin Pharmacol 59: 291-297.

6. Fujino H, Yamada I, Shimada S, Yoneda M (2001) Simultaneous determination of taxol and its metabolites in microsomal samples by a simple thin-layer chromatography radioactivity assay-inhibitory effect of NK-104, a new inhibitor of HMG-CoA reductase. J Chromatogr B Biomed Sci Appl 757: 143-150.

7. Kojima J, Fujino H, Yosimura M, Morikawa H, Kimata H (1999) Simultaneous determination of NK-104 and its lactone in biological samples by columnswitching high-performance liquid chromatography with ultraviolet detection. J Chromatogr B Biomed Sci Appl 724: 173-180.

8. Ojha A, Guttikar S, Vayeda C, Padh (2007) Determination of Pitavastatin from Human Plasma Using High Performance Liquid Chromatography with Fluorescence Detection. Se Pu 25: 715-718.
9. Satheesh Kumar N, Baghyalakshmi J (2007) Determination and Quantification of Pitavastatin Calcium in Tablet Dosage Formulation by HPTLC Method Analytical letters 40: 2625-2632.

10. Panchal HJ, Suhagia BN, Patel NJ, Patel BH (2008) A simple and sensitive HPTLC method for quantitative analysis of pitavastatin calcium in tablets. $J$ Planar Chromatogr 21: 267-270.

11. Panchal HJ, Suhagia BN, Patel MM, Patel BH (2009) Estimation of pitavastatin calcium in tablet dosage forms by column liquid chromatography and ultraviolet spectrophotometry. J AOAC Int 92: 158-64.

12. Reviewer Guidance. Validation of analytical procedures-methodology, 1994.

13. ICH/CPMP guidelines Q2B, Validation of Analytical ProceduresMethodology.1996.

14. ICH International conference on Harmonization .Validation of Analytical Procedures: Methodology. 1996.

15. Grushka E , Brown PR, Brown R (2000) Advances in chromatography, 40: 443 454.

16. Ahuja S, Scypinski S (2001) (Eds) Handbook of Modern Pharmaceutical Analysis, Academic Press, New York, 415-443 